\title{
TRTaKaDEMi
}

ISSN 2149-9446 | Cilt 06 | Sayı 12 | Mayıs 2021 | Dijital Hayat ve Etik

\section{Dijital Dünyada Kişisel Veri ve Etik: Gizlilik Politikası Bağlamında "\#WhatsAppSiliyoruz" Krizinde Kullanıcı Tepkilerini Anlamak}

\author{
Eda TURANCI*
}

\begin{abstract}
Öz
Her kriz çeşitli biçimlerde kişi ya da kurumları etkileyebilmekte, bu etkiler de farklı tepkilerin üretilmesine sebep olabilmektedir. Kamuoyunun tepkilerini incelemek, krizin kamusal alana nasıl yansıdığını ve değerlendirildiğini anlamak açısından önemlidir. Öte yandan son yıllarda dijital platformların gündelik yaşamdaki hâkimiyeti tartışmasız bir gerçektir. Dijital platformlar; sosyalleşmek, iletişim kurmak, eğlenmek, tepki ve düşünceleri paylaşmak, kendini ifade etmek gibi amaçlara hizmet etmekte ancak bir yandan da çeşitli sorunları gündeme getirmektedir. Son yıllarda sıkça tartışılan veri gizliliği ile kişisel verilerin korunması, paylaşılması ve depolanması konusu, dijital uygulamalar açısından hem etik hem de hukuki boyutları olan bir konudur. Kişisel verilerin saklanması, farklı mecralarla paylaşıması ve veri gizliliği bağlamında tartışılan WhatsApp krizi, çalışmanın konusunu oluşturmaktadır. Çalışmada, krize ilişkin kullanıcı tepkilerinin incelenmesi amaçlanmış olup bu amaçla Twitter'da \#WhatsAppsiliyoruz hashtagi ile yapılan paylaşımlar, içerik analizi yöntemi ile incelenmiştir. İnceleme sonucunda tweetlerde en çok "mizahi" unsurlara yer verildiği, ikinci sırada "tepki" tweetlerinin ve üçüncü sırada "tepkileri eleştiren" tweetlerin olduğu görülmüştür. Konuya karşı tepki gösterme amaçlı atılan tweetlerin en çok "kişisel verilerin kullanılması sorununa" gönderme yaptı̆ı̆, "dayatma", "ayrımcılık" ve "güven kaybı, ihanet" vurgularına ise yakın oranlarda yer verildiği anlaşılmıştır. Tepkiyi eleştirmek amacıyla atılan tweetlerde ise en çok "tüm uygulamaların kişisel verileri kullandığı gerçeğine" dikkat çekildiği bulgulanmıştır.
\end{abstract}

Anahtar Kelimeler: Etik, Kişisel Veri, Gizlilik Politikası, WhatsApp, İçerik Analizi

\section{Araştırma Makalesi}

Geliş Tarihi: 28.03.2021

Kabul Tarihi: 24.05.2021

* Dr. Öğr. Üyesi, Ankara Hacı Bayram Veli Üniversitesi Iletişim Fakültesi, Halkla illişkiler ve Tanıtım Bölümü, edaturanci@hotmail.com 


\title{
TRTAKaDeMi
}

ISSN 2149-9446 | Volume 06 | Issue 12 | May 2021 |Digital Life and Ethics

\section{Personal Data and Ethics in the Digital World: Understanding User Reactions in the "\#WhatsAppSiliyoruz" Crisis in the Con- text of the Privacy Policy}

\author{
Eda TURANCI
}

\begin{abstract}
Each crisis can affect individuals or institutions in various ways, and these effects can lead to the production of different reactions. It is important to examine the reactions of the public in terms of understanding how the crisis is reflected and evaluated in the public sphere. On the other hand, the dominance of digital platforms in daily life is an indisputable fact in recent years. Digital platforms serve purposes such as socializing, communicating, having fun, sharing reactions and thoughts, but on the other hand, they causes various problems. The issue of data privacy and protection, sharing and storage of personal data, which has been discussed frequently in recent years, is an issue that has both ethical and legal dimensions. The WhatsApp crisis, discussed in the context of storing personal data, sharing it with different channels, and data privacy, is the subject of the study. In the study, it was aimed to examine user reactions to the crisis, and for this purpose, the posts made on Twitter with the hashtag \#WhatsAppSiliyoruz (\#deleteWhatsApp) were examined through the content analysis method. As a result of the analysis, it was seen that the most "humor" element was used in tweets. The second was "reaction" and the third was the "criticizing the reactions" tweets. It has been understood that the tweets sent to react mostly refer to the "problem of using personal data", while the emphasis on "imposition", "discrimination" and "loss of trust-betrayal" are used at close rates. In the tweets posted to criticize the reaction, it was found that the most attention was drawn to the "fact that all applications use personal data".
\end{abstract}

Keywords: Ethics, Personal Data, Privacy Policy, WhatsApp, Content Analysis

Research Paper

Recieved: 28.03.2021

Accepted: 24.05.2021 


\section{Giriş}

Dijital platformlar, kullanıcıların edilgen tüketici/alıcı konumundan içerik üretme sürecine geçişlerini mümkün kılan yapısı nedeniyle daha katılımcı bir alan olarak değerlendirilmektedir. Bu doğrultuda kullanıcılar; tepki, düşünce, içerik üretme potansiyeline sahip, birbirleriyle iletişim ve etkileşim kuran, sosyal bir bağ hisseden özneler olarak da görülebilir. Öte yandan dijital teknolojilerin ve iletişim araçlarının yoğun olarak kullanıldığı günümüzde ortaya çıkan krizlerin bir kısmı da bu teknolojiler etrafinda belirmekte ve tartışılmaktadır. Dijital platformların ve uygulamaların insan hayatında artan önemi, platformların yaşamın her alanında kullanılmasını beraberinde getirmiş ve bu durum da dolaylı olarak büyük miktarda verinin dijital araçlar yoluyla transferini, depolanmasını ve saklanmasını sağlamıştır. Pek çok farklı bilgiyi içeren bu veriler, başlı başına ekonomik bir değer olma özelliği taşırken özellikle ticari işletmeler için bu verilere erişim, işlevsel ve kazançlı bir alan hâline gelmiştir. Öte yandan bu veriler, kullanıcıların uygulamaları kullanırken üretmiş oldukları kişisel verileri de kapsayan devasa bilgi kümeleridir. Bu doğrultuda kişisel verilerin paylaşımı ve saklanması, başta etik olmak üzere pek çok sorunun gündeme gelmesine neden olmuştur. Son yıllarda çeşitli yasal düzenlemeler ile korunmaya çalışılan kişisel veriler ve bununla bağlantılı olarak sağlanmaya çalışılan veri gizliliği, dijital dünyanın dikkat çeken tartışma başlıklarındandır.

Kişisel verilere ilişkin tartş̧manın bir ayağını ise verinin asli sahibi olan kullanıcılar oluşturmaktadır. Kullanıcılar açısından mahremiyet, özel hayatın gizliliği, temel hak ve özgürlüklerin korunması gibi başlıklar üzerinden tartışılabilir olan konu, dijital platformlar özeline indirgendiğinde ise tartsşma verilerin ticari amaçlarla kullanılması çerçevesinde açığa çıkmaktadır. Bu kapsamda bakıldığında dijital platformların kullanıcılarına sunduğu gizlilik politikaları ile kullanıcı sözleşmeleri temelde, kullanıcılara sahip olduğu hakları anlatan ve kişisel verilerin neden ve nasıl toplandığını, saklandığını, işlendiğini, kimlerle paylaşıldığını, veri güvenliğinin nasıl sağlandığını ve bu veriler ile ne yapıldığını açıklayan metinlerdir. Uygulamayı kullanmaya devam edebilmek için sözleşmelerin kullanıcılar tarafindan onaylanması ise kısaca kullanıcının, kendisine aktarılan bilgileri okuduğunun, anladığının ve rıza gösterdiğinin işaretidir.

Çalışmanın konusu olan WhatsApp krizi, kişisel verilerin işlenmesi ve veri gizliliği bağlamında ortaya çıkmış, toplumsal ile bireysel tepkiler üzerine inşa olmuş ve etik bir sorundan temellenen bir krizdir. Popüler uygulamalardan olan WhatsApp'ın gizlilik politikasını ve kullanım koşullarını değiştirdiğini duyurarak verileri Facebook ile paylaşacağını ilan etmesinin ardından gündeme oturan tartışmaların pek çok odak noktası olmakla birlikte bu odak noktalarından biri de kullanıcıların durum karşısın- 
da gösterdikleri tepkilerdir. Özellikle krizin merkezinde, verinin üreticisi ya da farklı bir ifadeyle sahibi olan kullanıcıların bulunması konuyu kullanıcılar perspektifinden ele almayı gerektirmektedir. Ortaya çıkan krizle bağlantılı olarak \#WhatsAppSiliyoruz paylaşımları ile kullanıcıların bir araya gelmesi, dijital platformların katılımcılık kültürüne olan etkisinin de bir göstergesi olarak değerlendirilebilir. Hashtag kullanımı, pek çok insanı bir araya getiren bir ortak payda olarak değerlendirilebilmekle birlikte bu hashtagin taşıdığı mesaj da olaya karşı bir tepki içermektedir. Bu açıklamalar ışığında çalışmanın amacı, WhatsApp krizi çerçevesinde ortaya çıkan kullanıcı yorumlarının, tepkilerinin ve eleştirilerinin incelenmesidir. Bu inceleme, kullanıcıların kendi kişisel verilerinin paylaşılmasına, kullanılmasına ve aktarılmasına ilişkin bakış açılarını anlamak, ortaya koydukları tepkiyi değerlendirmek, kişisel verilerin gizliliğine gösterilen önemi analiz edebilmek ve kişisel veri, veri gizliliği ile etik arasındaki ilişkiyi kurmak açısından önemlidir.

\section{Kişisel Veri, Etik ve Dijital Uygulamalar İlişkisi}

Dijital dünyanın sunduğu imkânlar, platformların ve uygulamaların önemli bir avantajı olarak değerlendirilmektedir. Öte yandan sosyal ağlar ve dijital platformlar, kişilerin bilgilerini paylaştıkları, haberleştikleri, bilgi alışverişinde bulundukları, zaman geçirdikleri, çeşitli ihtiyaçlarını karşıladıkları ve başka pek çok farklı amaçla kullandıkları araçlardır. Bu doğrultuda dijital araçlar hem çok sayıda verinin depolandığı hem de pek çok verinin transferini sağlayan sistemlerdir. Dijital dünyada var olan bu veri bolluğu, farklı perspektiflerden tartışılmakta ve incelenmektedir. Çok boyutlu olan konu, büyük veri ekseninde de tartışılabilmekte ve Marr'ın açıklamasıyla kavram, dijital dünyada yer alan verinin hacmine, hızına, çeşitliğine ve doğruluğuna işaret etmekte ve iş dünyası da dâhil olmak üzere farklı alanların bu verilerden faydalanma becerisini açıklamaktadır. Ancak burada önemli olanın ne kadar veriye sahip olunduğundan öte, verinin iyi kullanılıp kullanılmaması olduğu vurgulanmaktadır (Marr, 2020: 10, 126-127). Bahsedilen bu verilerin önemli bir çoğunluğu ise kullanıcıların platformları kullanırken ürettikleri kişisel verilerdir.

Kişisel veri, Kişisel Verilerin Korunması Kanunu'nda (2021), "kimliği belirli veya belirlenebilir gerçek kişiye ilişkin her türlü bilgi" olarak tanımlanmaktadır ve açıklandığı gibi özel hayatın gizliliği ile kişilik hakları gibi temel özgürlüklerle ilişkilidir. Ancak günümüzdeki yeni kitle iletişim araçlarının özel hayatın gizliliğini koruma kapasiteleri düşüktür (van Dijk, 2016: 35). Kişisel veri, aynı zamanda mahremiyet ile de ilgili olup özellikle dijital dünyada artan veri ihlallerinin bireylerde mahremiyet endişesine yol açabileceği vurgulanmaktadır (Öz ve Kılıç, 2020). Bilir'in (2021: 178) ifade ettiği gibi "teknolojinin ilerlemesi, kişisel veriler üzerinde her türlü işlemin 
yapılmasını mümkün" hâle getirirken kişisel verilerin izinsiz kullanılması hukuki ve etik bağlamda sorunlar yaratmaktadır. Ancak dikkat çekmek gerekir ki Kişisel Verilerin Korunması Kanunu'nda (2021) kişisel verilerin işlenebilmesi için kişilerin açık rızasının gerektiği açıklanmıştır.

Dijital teknolojiler, internet, sosyal medya, çevrim içi platformlar ve veri yığınları arasında doğrudan bir ilişki olduğu açıktır (Narin vd., 2017; Ergen, 2018). Dijital dünyada var olan bu veri bolluğu, iletişim ve pazarlama sektörü, reklamcılık ve halkla ilişkiler çalışmaları, bankacılık ile güvenlik gibi pek çok alanda varlık gösteren kurum ve araştırmacı için işlevsel bir alan yaratmaktadır (Doğan ve Arslantekin, 2016). Markalar ve sektörler açısından da kazancı, kârlılığı ve rekabeti arttıran pek çok verinin geleneksel mecralara göre çok daha kolay edinildiği dijital sistemlerde, bir haberin ne kadar okunduğu, kaç kez tıklandığı, sayfada kalış süresi, kullanıcı yorumları ile izlenme oranları (Narin vd., 2017: 220) gibi bilgilerin yanı sıra hangi reklama tkklandığı, hangi siteden hangi ürünlerin satın alındığı, tüketicilerin tercihleri, beklentileri, geri bildirimleri gibi çok sayıda verinin bir araya getirilmesi ve ölçümlenmesi mümkündür. Marr’ın (2020: 19) açıkladığı gibi işletmeler için veriler, "karar verme sürecini ve faaliyetleri geliştirme ile veriyi parasallaştırma" açısından önemlidir.

Çevrim içi alanlar, tüketici davranışlarından politik tutum ve siyasi görüşlere kadar pek çok konuda doğal olarak oluşan büyük miktarda veriyi saklamaktadır (Townsend ve Wallace, 2016). Dijital dünyada hiçbir verinin silinemeyeceği gerçeğinden hareketle sürekli olarak depolanan ve elde edilmesi görece daha kolay olan bu veri yığını karşısında, sektörler de bu birikimi avantaja çevirmek istemekte ve verilerin ticari ile ekonomik amaçlarla kullanılması yönelimi artmaktadır. Benndorf ve Normann'ın (2018: 1260) belirttikleri gibi, bir yandan işletmeler, hükûmetler ve bilimsel araştırma kurumları gibi kurumlar büyük veri kümelerine yatırım yapmakta, bir yandan da özel verilerin ticari kullanımları konusundaki endişeler artmaktadır. Verilerin ticari maksatlar ile işlenmesi önemli bir tartş̧ma olmakla birlikte Öztürk (2015) sosyal medya ve etik arasındaki ilişkiyi incelediği çalışmasında, özel yaşamın gizliliği, kişisel veri güvenliği, telif hakları, reklam içeriklerinin yoğunluğu, yanıltıcı haber, nefret söylemi ve dijital gözetim gibi pek çok farklı etik soruna dikkat çekmektedir.

Bunların yanı sıra dijital uygulamalar ile sosyal medya ağları da ekonomik kazanç amacı güden işletmelerdir. Bu işletmeler, verinin akışını sağlayan araçlar olarak ekonomik değerin üretilmesine de aracılık etmektedir. Quinn ve Epstein'in (2018: 360, 361) ifadeleriyle, "Gizlilik, sosyal medya dünyasının fiili para birimi hâline gelmiştir." ve sosyal medyanın hızla benimsenmesi ile birlikte özel bilgilerin dijital hizmetler için ekonomik manada artan kullanımı, mahremiyet etrafindaki kavramsal çalışma- 
ları yeni sınırlara itmiştir. Marr (2020: 52-53) ise, "verinin kendisinin bir değer" olmasını ve "bilginin kendi içinde artan değerini" açıklamak için "bilginomi" (infonomics) kavramından bahsetmekte ve kavram, "bilgiyi yönetme ve muhasebeleştirme konusunda ortaya çıkan disiplini” (Gartner, 2021) açıklamak için kullanılmaktadır.

Kişisel verilerin korunması ve veri gizliliği, oldukça kapsamlı ve disiplinler arası bir konudur. Konunun başta hukuki olmak üzere geniş bir perspektiften ele alınması gerekmektedir ancak her çalışma, kapsamı gereği belli sınırlılıklar içerir. Çalışma, hukuki bir tartışma yürütme iddiası taşımamakta ve kişisel verilerin farklı mecralar ile paylaşılması tartışmalarından dolayı gündeme gelen bir krize yönelik tepkilerin incelenmesini amaçlamaktadır. Dijital uygulamalar ve kişisel veri arasındaki ilişki, mahremiyet ve özel alan gibi kavramlar üzerinden de yürütülebilir. Sosyal ağlar ve dijital platformlar, bireyin özgür iradesiyle paylaşım yaptı̆̆ ve bilgilerini paylaşth̆̆ alanlardır ancak "sosyal medya verileriyle ilgili en büyük endişe, bu tür verilerin herkese açık veya özel veri olarak kabul edilip edilmeyeceğine" (Townsend ve Wallace, 2016: 5) ilişkindir. Bu noktada "kamusal" ve "özel" arasında ayrım bulanıklaşmaktadır (Lomborg, 2012: 22). Genel anlamda sosyal ağlarda paylaşılan bilgiler kamuya açık alenileştirilmiş veriler olarak değerlendirilmekle birlikte, bu verilerin izinsiz ya da uygun olmayan biçimlerde kullanılması etik sorunlar doğurmaktadır.

Bu sorunların önüne geçmek için ise uygulamaların hemen hepsi kullanıcılarına, kullanım koşullarını ve gizlilik politikalarını açıklayan sözleşmeler sunmakta ve kullanıcıların bu sözleşmeleri kabul ettikten sonra programı kullanmaları istenmektedir. Ancak günümüzde pek çok kullanıcının bu sözleşmeleri okumadan kabul ettikleri ya da içeriklerine tam olarak hâkim olmadıkları varsayılabilir. Custers, van der Hof ve Schermer tarafindan 5,124 kişi ile yapılan araştırma sonuçlarına göre gizlilik politikalarını okuduklarını söyleyenlerin ancak \%21'i sözleşmeyi tamamen anladıklarını, \%42'si ise sözleşmenin çoğu kısmını anladıklarını belirtmişlerdir. Gizlilik politikalarını okuyanların \%12'si ise sözleşmeleri anlayıp anlamadıklarına ilişkin kararsızıı yaşarken hiç anlamadığını söyleyenlerin oranı \%5'tir. Ancak aynı çalışma, araştırmaya katılanların \%26'sının gizlilik politikalarını hiçbir zaman, \%27'sinin nadiren ve \%19'unun ise bazen okuduğunu bulgulamıştir (Custers vd., 2014: 280). Bulguların da gösterdiği gibi gizlilik politikalarının ve/veya kullanıcı sözleşmelerinin genel olarak okunmadığını söylemek mümkündür. Ancak McKinsey (Anant vd., 2020) tarafından yürütülen bir araştırmanın sonuçları, kullanıcıların ne tür verileri paylaştıkları ve bunları kiminle paylaştıkları konusunda giderek daha bilinçli hâle geldiklerini ortaya koymuştur. 


\section{Tepkilerin Dijital Platformlar Aracılığıyla Sunumu}

Her kriz, doğrudan veya dolaylı olarak pek çok insanı etkilemekte, pozitif ya da negatif yönde farklı tepkilerin, şikâyetlerin veya eleştirilerin üretilmesine yol açmaktadır. Bir kriz atmosferinde, insanların konuyla ilgili ne söylediklerini incelemek, konuya ilişkin algıları ve tepki odaklarını anlamak açısından önemli veriler sunabilmektedir. Tepkilerin farklı kanallar aracılığıyla dile getirilmesi mümkün olmakla birlikte, dijital platformlar kendine özgü doğası ve iletişimi dönüştürücü etkileri sayesinde fikir, düşünce ve görüşlerin paylaşıldığı araçların başında gelmektedir.

Dijital platformlara ilişkin temel tartş̧ma odaklarından biri, kullanıcıların içerik üretmelerine ve aktif katılıma imkân veren bir yapıya sahip olmalarıdır. Sürece dâhil olabilme imkânı, bir yandan katılımı mümkün kılarken bir yandan da "katılımcı kültür" ile "iletişim ortamının demokratikleşmesi" çerçevesinde tartı̧̧malar yaratmıştrr (Ateşalp ve Başlar, 2015: 162). Jenkins (2006: 3) katilımcı kültürün, "eski pasif medya izleyiciliği" kavramıyla yorumlandığını belirtmekte ve iletişim alanındaki dönüşüme paralel olarak arttk "medya üreticilerinden ve tüketicilerden ayrı roller üstlenenler olarak bahsetmek yerine, arthk onları hiçbirimizin tam olarak anlayamadığı yeni bir kurallar dizisine göre birbirleriyle etkileşime giren katılımcılar olarak görebilmenin" mümkün olduğunu açıklamaktadır. Yakınsama kavramı üzerinden de yazarın tartş̧tğı bu kuramsal perspektif, "tüketicilerin yeni bilgiler aramaya ve dağınık medya içeriği arasında bağlantllar kurmaya teşvik edildiği kültürel bir değişimi temsil” etmektedir (Jenkins, 2006: 3). İçerik oluşturma, başkalarıyla paylaşma ve sosyal bağlant hissi ile karakterize edilen katılımcı kültür, üretim, tüketim ve içeriğin bir araya geldiği ve yakınlaştğı yer olarak tanımlanmaktadır (Ciszek, 2013: 188). Castells'in (2016: 172) Jenkins'e atfen açıkladığı gibi yakınlaşma (yakınsama), yalnızca teknolojik ya da örgütsel olmadığı gibi bunlar sürecin yalnızca maddi boyutlarıdır ancak asıl yakınlaşma, temelde kültüreldir ve birbirleriyle iletişim kuran öznelerin zihinlerinde gerçekleşmektedir. Katılımcı kültürde ise içerik üreticisi konumunda olan üyeler katkılarının önemli olduğuna inanırken bir dereceye kadar da birbirleriyle sosyal bir bağ hissetmektedirler (Jenkins, 2009: 5-6). Bu açıdan Castells'in $(2016: 164,167,169)$ açıklamalarıyla iletişim içindeki özneler, yalıtılmıs varlıklar olmadıkları gibi aksine "ortak anlam üreten iletişim ağları kurarak kendi aralarında etkileşim kuran" yaratıcı izleyiciler ya da takipçiler olarak tanımlanabilir ve internete dayalı iletişim ağları sayesinde aslında mesajı gönderen ile alanın, "kolektif olarak aynı özne" olduğunu belirtmek mümkündür.

Literatürdeki farklı çalışmalar dijital uygulamalar ile katılımcı kültür arasındaki ilişkiye dikkat çekmektedir. Buna göre katılımcı kültür açısından YouTube (Chau, 2010; Ciszek, 2013; Burgess ve Green, 2018) ve Twitter (Smitko, 2012; Park, 2013) gibi 
platformlar önemli imkânlar sunarken bunlar gibi çok sayıda platform bir yandan da kullanıcılarına geniş ölçekli çevrim içi sosyal katılım firsatı yaratmaktadır (Rotman vd., 2011). Örneğin "Sosyal Linç ve Marka Krizleri Araştırması" (Zenna ve RepMan, 2018) raporu, insanların tepkilerini gösterdikleri ve sosyal linçlerin oluşmasında en etkili mecraların başında Twitter'ın geldiğini ortaya koymuştur. Bu kapsamda Twitter, çeşitli yollarla kullanıcıların aktif olarak içerik oluşturdukları bir platform olarak değerlendirilirken özellikle kullanılan hashtagler, iletişim ağının kurulmasını sağlayan bir işleve sahiptir. Buradan hareketle Castells (2016: 164), "izleyici” ya da "takipçi" kavramları etrafinda şekillenen söylemin yanlış inşa edildiğinden hareketle bu söylemin bireyi "mesajların edilgin hedefleri" olarak benimsediğini vurgulamaktadır.

Dijital platformların kendini ifade etme aracı olarak kullanılması aynı zamanda, özellikle gençlerin seslerini duyurmak için yeni mekanizmalar aramasından da kaynaklanmakta ve bu durum, bir yandan da daha eğlenceli bir aktivizm tarzını ortaya çıkarmaktadır (Jenkins vd., 2016: 2). Chau (2010: 65) ise literatürde yer alan pek çok araştırmanın sanal alanları, "gençlerin akranlarıyla bağ kurduğu, kamusal söylemle meşgul olduğu, kimliklerini keşfettiği ve yeni beceriler edindiği" alanlar olarak gördüğünü aktarmıştır. Bu açıklamalar, bir yandan da dijital aktivizm tartş̧malarını da anımsatmaktadır. Tepkilerin dijital platformlar aracılığıyla sergilenmesi olarak da görülebilecek dijital aktivizm kavramı kısaca, teknolojilerin yayılım hızından faydalanarak tepki gösterilen konular hakkında "yüksek kamuoyu sesi üretebilmek" amacıyla tasarlanmış eylemler (Kırık ve Özcan, 2014: 66) şeklinde tanımlanmaktadır.

Bununla paralel olarak çalışmanın konusu olan \#WhatsAppSiliyoruz tweetleri, hashtag aktivizmi kapsamında da değerlendirilebilir. Tombleson ve Wolf'un (2017: 15) aktardıkları gibi hashtag aktivizmi, "bir konu hakkında farkındalık yaratmak ve sosyal medya aracılığıyla tartışmayı teşvik etmek için hashtag kullanarak, bir amaç için mücadele etme veya destekleme eylemi" olarak tanımlanmaktadır. Hashtag kullanımı bir yandan da söyleyecek sözü olanın tartışmaya katılmasını, bir odak noktası bağlamında düşüncelerin yayılımını, ortak bir payda üzerinde ilişki ve iletişim kuralmasını ve dolaylı olarak da konuya ilişkin içerik üretilmesini sağlamaktadır. Geleneksel medyaya göre dijital medyanın interaktif yapısı ise potansiyel güç dengesinin kullanıc lehinde değişebilmesine olanak sağlamaktadır (van Dijk, 2016: 22). Dijitalin kullanıcılarına sağladığı bu avantaj daha etkileşimsel bir bilgi alışverişini mümkün kılarken Jenkins'in (2006: 24) açıkladığı gibi, "Yeni teknolojilerle güçlendirilmiş ve eski ile yeni medyanın kesişme noktasında yer alan izleyiciler, kültüre katılma hakkı talep etmektedirler." Tepkiler farklı boyutlarda olabileceği gibi genel- 
likle etik dışı veya haksız uygulamalara karşı kullanılan en ileri taktiklerden biri de boykottur (Özdemir Çakır, 2011; Makarem ve Jae, 2016). Belirli bir amaca erişebilmek için ürün, marka ya da hizmeti tercih etmekten kaçınmak olarak açıklanabilen boykot, uluslararası veya bölgesel çapta olabileceği gibi, kısa, orta ve uzun vadeli boykotlardan da bahsedilebilmektedir (Friedman, 1999). Sonuç olarak bu açıklamalar ışığında çalışmanın konusu olan WhatsApp krizini ve bu kriz etrafinda atılan \#WhatsAppSiliyoruz paylaşımlarını, dijital platformlarda ortaya çıkmış bir tepki ve eylem biçimi olarak değerlendirmek, uygulamayı silmeyi ise bu tepkinin somut çıktısı olarak varsaymak mümkündür.

\section{WhatsApp Krizi: Genel Bir Bakış}

WhatsApp krizi, başı başına etik bir tartışmanın ürünü olan kişisel verilerin kullanılması ve paylaşılması tartışması üzerine temellenmektedir. Buna göre popüler bir mesajlaşma, arama ve haberleşme uygulaması olan WhatsApp, "180'den fazla ülkede ve 2 milyardan fazla kişinin kullandığı" (WhatsApp, 2021a) bir uygulamadır. Kullanıcılarına ücretsiz olarak hizmet veren, mesaj, fotoğraf, belge, video, konum, kişi paylaşma gibi özellikleri olan uygulama, rakiplerine kıyasla en çok tercih edilen uygulamadır (Statista, 2021). 2014 yılında Facebook tarafindan satın alınan uygulama, Facebook şirketlerinden biri olmasının yanı sıra Messenger ve Instagram gibi popüler uygulamaları da içeren bir yapının parçasıdır (Facebook, 2021).

4 Ocak 2021 tarihinde WhatsApp’ın veri paylaşım ve gizlilik politikasını değiştireceğini ve tüketicilere daha uygun reklam deneyimi sunmak için Facebook ile paylaşacağını açıklamasıyla kriz patlak vermiştir (WhatsApp, 2021b). Daha önce de belirtildiği gibi bu sözleşmeler aslında, "kullanıcıların tüm kişisel enformasyonunu depolamayı meşrulaştırmaya uygun zemin hazırlamaktadır" (Narin vd., 2017: 221). Kullanıcılarına, programı kullanmaya devam edebilmeleri için verilerini Facebook ile paylaşma onayı vermelerini içeren sözleşmeyi kabul etmeleri şartı getiren uygulama, sonrasında tepkilere ve eleştirilere maruz kalmıştır. Tepkiler sonrasında WhatsApp, sözleşmenin tarihini bir süreliğine ertelediğini duyurmuştur. Gündeme gelen bu olay, kişisel verilerin ve kullanıcı bilgilerinin ticari kullanımına ilişkin tartışmaları yeniden gündeme getirmiştir.

Bir başka tartışma ise sözleşmenin Avrupa Birliği ülkelerini kapsamadığı bilgisinin (Biber, 2021) yayılması üzerine patlak vermiştir. Dayatma olarak değerlendirilen sözleşmeye yönelik tepkiler sosyal ağlarda hızla yayılmıştır. Yalnızca Türkiye'de değil dünya çapında da tepkiyle karşılanan bu durum akabinde pek çok insan WhatsApp uygulamasını silerek Tesla CEO'su Elon Musk gibi ünlülerin de işaret ettiği alternatif platformlara yönelmeye başlamıştır (Dixit, 2021). 
Ortaya çıkan tepkiler sonucunda WhatsApp açıklamalarda bulunarak krizi yönetmeye çalışmıştır. Twitter resmî hesabından 12 Ocak 2021 tarihinde yapılan paylaşıma göre, özel mesajların uçtan uca şifreleme ile korunmasına devam edildiği vurgulanmış ve bahsedilen gizlilik politikası güncellemesinin özel mesajların gizliliğini etkilemediğine dikkat çekilmiştir (WhatsApp, 2021c). WhatsApp'ın ve benzer uygulamaların uçtan uca şifreleme özelliği kullanıcılarda "belirli bir düzeyde gizlilik algısı yaratmaktadır" (Barbosa ve Milan, 2019: 49).

Tepkilerden sonra Kişisel Verileri Koruma Kurulu ile Rekabet Kurulundan da soruşturmalar ve incelemeler gelmiştir. Rekabet Kurulu yayınladığı bilgilendirmede:

"Rekabet Kurulunun 11.01.2021 tarihli ve 21-02/25-M sayılı kararıyla, WhatsApp kullanıcılarına getirilen veri paylaşma zorunluluğu hakkında Facebook Inc., Facebook Ireland Ltd., WhatsApp Inc. ve WhatsApp LLC (hepsi birlikte "Facebook" olarak anılacaktr) hakkında 4054 sayılı Rekabetin Korunması Hakkında Kanun'un 6. maddesinin ihlal edip edilmediğinin tespiti amacıyla resen soruşturma açılmıştır.

\section{$[\ldots]$}

Alınan kararda ayrıca söz konusu uygulamaların soruşturma sonucunda alınacak nihai karara kadar ciddi ve telafi olunamayacak zararlar doğurma ihtimalini haiz olduğundan 4054 sayılı Kanun'un 9. maddesi çerçevesinde geçici tedbir alınması ve bu kapsamda Facebook'un Türkiye'de WhatsApp kullanıcılarının verilerinin 8 Şubat 2021 tarihinden itibaren başka hizmetler için kullanılmasına yönelik getirdiği koşulları durdurması ve bu koşulları kabul eden veya bilgilendirmeyi alarak kabul etmeyen tüm kullanıcılara Facebook'un veri paylaşımını içeren yeni koşulları durdurduğunu anılan tarihe kadar bildirmesi gerektiğine karar verilmiştir." ifadelerine yer vermiştir (Rekabet Kurulu, 2021).

Kişisel Verileri Koruma Kurumu (2021) 12 Ocak tarihinde yayınladığı duyurusunda ise:

“[...] Gizlilik politikasında ise hangi verilerin hangi amaçlarla işleneceği ifade edilmekle birlikte, işlenen kişisel verilerin WhatsApp Inc. tarafindan yurt dışında yerleşik bulunan hizmet aldığı ve hizmet verdiği Facebook grup şirketleri, tedarikçileri, iş ortakları, hizmet sağlayıcıları ve diğer üçüncü taraf veri sorumluları gibi net olarak belirli olmayan taraflara teknik destek, teslimat ve diğer hizmetleri sağlamak, araştırma yapmak, pazarlama ve anket vb. gibi yine belirli olmayan amaçlarla aktarılacağının ifade edilmekte olduğu görülmektedir." ifadelerine yer vermiş, konuyla ilgili resen inceleme başlatıldığını duyurmuştur.

Kriz, Facebook'un kurucusu Mark Zuckerberg'in daha önce yaşamış olduğu Cambridge Analytica krizini de hatırlatmıştır. WhatsApp uygulamasının da Facebook'un bir parçası olması, krize yönelik algıyı da etkilemiştir. Facebook'un kullanıcı bilgilerini Cambridge Analytica şirketiyle paylaşması sonucu yaşananlar, benzer şekilde kişisel 
verilerin gizliliği tartışmalarını gündeme getirmiştir (Ergen, 2018). "Sosyal Linç ve Marka Krizleri Araştirması" (Zenna ve RepMan, 2018: 18) raporuna göre Türkiye'de de tepki çeken Cambridge Analytica krizi sonrası araştırmaya katılanların 25\%'i, o dönemde uygulamayı kullanmayı bıraktığını ancak şu anda kullanmaya devam ettiğini, \%46’sı ise sorun yaşamadığı sürece uygulamayı kullanmaya devam edeceğini belirtmiştir. Bu bulgular, krizlere yönelik tepkilerin ne kadar eyleme dönüştüğü sorusunu da gündeme getirmektedir.

\section{5. \#WhatsAppSiliyoruz Tweetleri Üzerine Bir Analiz}

Çalışmanın amacı, WhatsApp'ın kişisel verilerin işlenmesi ve paylaşılması kapsamında kullanıcı sözleşmelerinde değişiklik yapacağını ve uygulamayı kullanmaya devam edebilmek için sözleşmenin kabul edilmesi gerektiğini açıklamasından sonra ortaya çıkan krizin kullanıcı tepkileri boyutunu, etik bir perspektiften incelemektir. Etik bir sorun olan kişisel verilerin depolanması, saklanması ve paylaşılması konusu, kişisel verinin üreticisi ve kaynağı olan kullanıcılar açısından önemli bir sorundur. Bu doğrultuda amaç, kullanıcıların şahsi verileri ile ilgili olan bir kriz karşısında ürettikleri tepkileri, bu tepkilerin odak noktalarını, eleştirilerini, eleştirilerinin çerçevesini ve kullanıcıların kişisel verilerin güvenliğine yönelik düşünce ve fikirlerini analiz etmektir. Öte yandan çalışmanın kendisi de bir büyük veri kaynağı olan Twitter platformu üzerinden gerçekleştirilmektedir. Sosyal ağlar, araştırmacılara geniş kapsamlı verilere erişim açısından avantaj sağlamaktadır. Aynı zamanda Twitter'ın kullanıcıların tepkilerini en çok dile getirdikleri mecraların başında gelmesi de bu seçimde belirleyici olmuştur. Bu doğrultuda araştırma şu sorulara yanıt aramaktadır:

1) \#WhatsAppSiliyoruz tweetleri, hangi temel üst kategorileri içermektedir ve bunların dağılımları nasıldır?

2) Üst kategoriler altında dikkat çeken alt kategoriler nelerdir ve bunların dağılımları nasıldır?

3) Tweetlerde kullanıcıların dikkat çektiği diğer odak noktaları nelerdir?

4) Tweetlerde hashtag (\#) kullanımı ve alternatif platformlara yapılan göndermelere ilişkin dikkat çeken unsurlar nelerdir?

\subsection{Yöntem ve Örneklem}

Araştırmanın örneklemini temsil eden tweetler, Twitter API (Application Programming Interface-Uygulama Programlama Arayüzü) aracılığıyla elde edilmiş ve hashtag (\#) kullanılarak toplanmıştır. Twitter API, Twitter verilerine erişim sağlayan bir arayüz olmakla birlikte erişim için uygulamanın izin vermesi gerekmektedir. API eri- 
şimi ile \#WhatsAppSiliyoruz hashtagini içeren toplam 3.000 tweet analiz amacıyla derlenmiştir. Veriler, \#WhatsAppSiliyoruz hashtaginin Twitter'da mevcut zaman diliminde en çok konuşulan konular manasına gelen "trending topics" olduğu 9-11 Ocak $2021^{1}$ tarihleri arasından seçilmiştir.

Çalışmada içerik analizi yönteminden faydalanılmıştır. Gökçe'nin (2019: 33) tanımlamasıyla içerik analizi, "Mevcut olan iletişim boyutlarını analiz etmek ve buradan mevcut olmayan sosyal gerçekliğin belirli boyutlarına (kaynak-hedef-ortam) yönelik çıkarım yapmak amacıyla metinlerin içeriklerini analiz eden ve bu süreçte belirli kurallar çerçevesinde sistematik hareket eden bir yöntemdir." Berg ve Lune (2019: 344) ise neyin içeriği oluşturduğuna ilişkin soruya, "çeşitli amaçlar için insanlar tarafindan üretilmiş her şey" içeriktir yanıtını vermişlerdir. Çalışmada 3.000 tweetlik örneklemin tamamı, analiz için kodlanmıştır. Kodlama cetveli oluşturulmadan önce veri setinin ön okuması yapılmış, örneklemin yüzde 10'luk dilimini (bkz. O'Connor ve Joffe, 2020) temsilen 300 tweet kodlanarak kategoriler belirlenmiştir. İki araştırmacının eş zamanlı olarak kodlaması ile fikir ayrılığına düşülen yerler revize edilmiş ve cetvelin son hâli oluşturulmuştur (Tablo 1).

Tablo 1'de kodlama kategorileri ve kategorinin içeriği açıklanmaktadır. Bazı tweetlerin birden fazla kategoriyi temsil etmesi durumunda mesajın öncelikli vurgusu doğrultusunda tekli kodlama yapılmış ve her mesaj bir kategoriyi temsil edecek şekilde kodlanmıştır. Tweetlerde kullanılan emojiler ve fotoğraf-video gibi görseller de mesajı anlamak açısından yol gösterici olduğundan kodlama sırasında dikkate alınmıştır.

\footnotetext{
${ }^{1}$ Tarih aralıkları için bkz. http://trending-topics.co/search.php?u=\%23WhatsAppSiliyoruz https://getdaytrends.com/trend/\%23WhatsAppSiliyoruz/\#otherLocations https://archive.twitter-trending.com/turkey/09-01-2021
} 
Tablo 1. İçerik Analizi Kodlama Cetveli

\begin{tabular}{|c|c|}
\hline Üst kategoriler & $\begin{array}{l}\text { Tepki: Uygulamanın hayata geçirmek istediği değişime tepki gösteren, uy- } \\
\text { gulamayı sildiğini beyan eden, yeni kullandığı uygulamaya gönderme yapan } \\
\text { tweetleri içermektedir. } \\
\text { Tepkiyi eleştirme: Konunun abartıldığını, yanlış yorumlandığını, diğer uy- } \\
\text { gulamaların da verileri kullandığını ve güvenilir olmadığını, kullanıcıların } \\
\text { zaten çeşitli şekillerde kişisel verilerini verdiklerini vb. belirten tweetleri } \\
\text { içermektedir. } \\
\text { Mizah: Konuyu esprili bir dille ele alan tweetleri içermektedir. } \\
\text { Haber/bilgi: Konuyla ilgili bilgilendirme içeren veya herhangi bir habere } \\
\text { yönlendirme yapan tweetleri içermektedir. } \\
\text { Nötr: Ne yapılacağı hakkında kararsızlık ve karmaşanın olduğunu belirten, } \\
\text { soru soran ve pozitif veya negatif yönde fikir beyan edilmeyen tweetleri } \\
\text { içermektedir. } \\
\text { Alakasız: Konuyla ilgili olmayan ancak hashtagin kullanıldığı tweetleri } \\
\text { içermektedir. }\end{array}$ \\
\hline $\begin{array}{l}\text { Alt kategoriler } \\
\qquad \quad \text { Tepki }\end{array}$ & $\begin{array}{cl}\text { Tepki : Tepki içeren tweette spesifik bir vurgu varsa alt kategori kodlaması } \\
\text { yapılmıştir. Alt kategoriler: } \\
\checkmark & \text { Kişisel verilerin kullanılması sorunu } \\
\checkmark & \text { Dayatma } \\
\checkmark & \text { Ayrımcılık } \\
\checkmark & \text { Güven kaybı-ihanet } \\
\checkmark & \text { Spesifik vurgu yok }\end{array}$ \\
\hline $\begin{array}{ll}\text { - } & \text { Tepkiyi } \\
& \text { eleştirme }\end{array}$ & $\begin{array}{cl}\text { Tepkiyi eleştirme: Tepkileri eleştiren tweette spesifik bir vurgu varsa alt } \\
\text { kategori kodlaması yapılmıştı. Alt kategoriler: } \\
\checkmark & \text { Abartılı korku } \\
\checkmark & \begin{array}{l}\text { Tüm uygulamaların kişisel verileri kullanması gerçeği (uygulama- } \\
\text { ların ortaklığı) }\end{array} \\
\checkmark & \text { Verilerin tüketiciler tarafindan verildiği } \\
\checkmark & \text { Verilerin değersiz oluşu } \\
\checkmark & \text { Uygulamaya geri dönüş yapılacağı } \\
\checkmark & \text { Gündemdeki daha önemli konulara gönderme } \\
\checkmark & \text { Spesifik vurgu yok }\end{array}$ \\
\hline $\begin{array}{l}\text { Alternatif mecra vur- } \\
\text { gusu }\end{array}$ & $\begin{array}{l}\text { Var: Tweette metin içinde ya da hashtag ile herhangi bir başka mecraya } \\
\text { gönderme olan tweetler } \\
\text { Yok: Herhangi bir başka mecraya gönderme olmayan tweetler }\end{array}$ \\
\hline $\begin{array}{l}\text { Görsel (fotoğraf-vi- } \\
\text { deo) veya yönlendirici } \\
\text { link kullanımı }\end{array}$ & $\begin{array}{l}\text { Var } \\
\text { Yok }\end{array}$ \\
\hline Hashtag kullanımı & $\begin{array}{l}\text { \#WhatsAppSiliyoruz } \\
\text { \#WhatsAppSiliyoruz + \#WhatsAppSilmiyoruz }\end{array}$ \\
\hline
\end{tabular}

Güvenilirliği artırmak için iki araştırmacının ayrı ayrı kodladığı 300 tweet doğrultusunda kodlayıcılar arası güvenilirliği gösteren Krippendorff alfa $(\alpha)$ değeri hesaplanmıştır. Veri kümesinin boyutuna bağlı olarak veri birimlerinin \%10 ila 25'lik bir diliminin çoklu kodlanması, güvenilirlik hesaplamalarında uygun bir yöntemdir (O’Connor ve Joffe, 2020: 5). Neuman'ın (2014: 376) belirttiği gibi Krippendorff $\alpha$, her sayıdaki kodlayıcı, her türdeki değişken, herhangi bir örneklem boyutu ve 
eksik verinin varlığı gibi durumlarda da kullanılabildiğinden en yaygın güvenilirlik ölçüsüdür ve gözlenen uyumsuzluğun (Do), beklenen uyumsuzluğa (De) bölünmesinden sonra 1'den çıkarılması ile hesaplanmaktadır.

Hayes ve Krippendorff'un (2007) çalışmalarında açıkladıkları yöntemle, içerik analizi kategorilerinin her biri için ayrı ayrı $\alpha$ değerleri hesaplanmıştır. Buna göre, "üst kategoriler" için $\alpha=0.89$, "tepki" alt kategorileri için $\alpha=0.85$, "tepkiyi eleştirme" alt kategorileri için $\alpha=0.92$, "alternatif mecra" kategorisi için $\alpha=0.95$, "görsel veya link kullanımı" kategorisi için $\alpha=0.94$ ve son olarak "hashtag kullanımı" kategorisi için $\alpha=0.95$ bulunmuştur. Alfa değerinin " 1 "e eşit olması, mükemmel güvenilirlik anlamına gelirken $\alpha$ değerinin 0.80 değerinin üstünde olması yüksek güvenilirlik olarak kabul edilmektedir. Buna göre, 0.81 ile 1 arasındaki değerler, "neredeyse mükemmel uyuma” (O'Connor ve Joffe, 2020) işaret etmektedir. Bu doğrultuda çalışmanın yüksek güvenilirliği olduğu söylenebilir. Örneklemin tamamı IBM SPSS 22 programı ile kodlanmıştır. Sosyal ağlardan elde edilen verilerin kişisel bilgiler de içermesi, akademik çalışmalar açısından dikkat edilmesi gereken bir konudur. Buna göre çalışmada tweet sahiplerine, kullanıcılara veya kişisel bilgilere ilişkin herhangi bir bilgi analiz edilmediği gibi anonimleştirilmiş şekilde kodlanan tüm veriler, kullanıc bilgilerinden bağımsız olarak değerlendirilmiştir.

\section{Bulgular}

İncelenen tweetlerin üst kategorilerinin genel dağılımlarına bakıldığında, en çok paylaşımın mizah kategorisinde ( $n=987, \% 32,9)$ olduğu görülmektedir. İkinci sırada kriz karşısında gösterilen tepki tweetleri ( $n=693, \% 23,1)$ dikkat çekerken üçüncü sırada ise tepkileri ve krizin ele alınış biçimini eleştiren ( $n=437, \% 14,6)$ tweetlerin yer aldığı bulgulanmıştır (Tablo 2).

Tablo 2. Üst Kategorilerin Dağılımı

\begin{tabular}{|l|c|c|}
\hline Üst Kategoriler & $\mathrm{n}$ & $\%$ \\
\hline Mizah & 987 & 32,9 \\
\hline Tepki & 693 & 23,1 \\
\hline Tepkiyi eleştirme & 437 & 14,6 \\
\hline Haber/bilgi & 342 & 11,4 \\
\hline Alakasız & 333 & 11,1 \\
\hline Nötr & 208 & 6,9 \\
\hline & 3.000 & 100,0 \\
\hline
\end{tabular}

Tablo 2 incelendiğinde, haber/bilgi içeren tweet oranı ile alakasız tweet oranlarının birbirine yakın olduğu görülmüştür. Haber/bilgi amacıyla atılan tweetler, incelenen tüm tweetlerin \%11,4'ünü oluşturmaktadır. \#WhatsAppSiliyoruz hashtaginin 
kullanıldığı tweetlerin \%11,1'inin ise konuyla alakasız tweetler olduğu ancak ilgi çekmek, tanıtım veya reklam yapmak, konunun popülaritesinden faydalanmak gibi amaçlarla hashtagin kullanıldığı anlaşılmıştır. Yalnızca \%6,9'luk bir tweetin negatif ya da pozitif yönde bir fikir beyan etmeden bilgi aramak, soru sormak ya da yaşadığı kararsızlık-karmaşayı aktarmak amacıyla atıldığı anlaşılmıştır.

Grafik 1. Tepki Tweetlerinin Alt Kategorilerinin Dağılımı

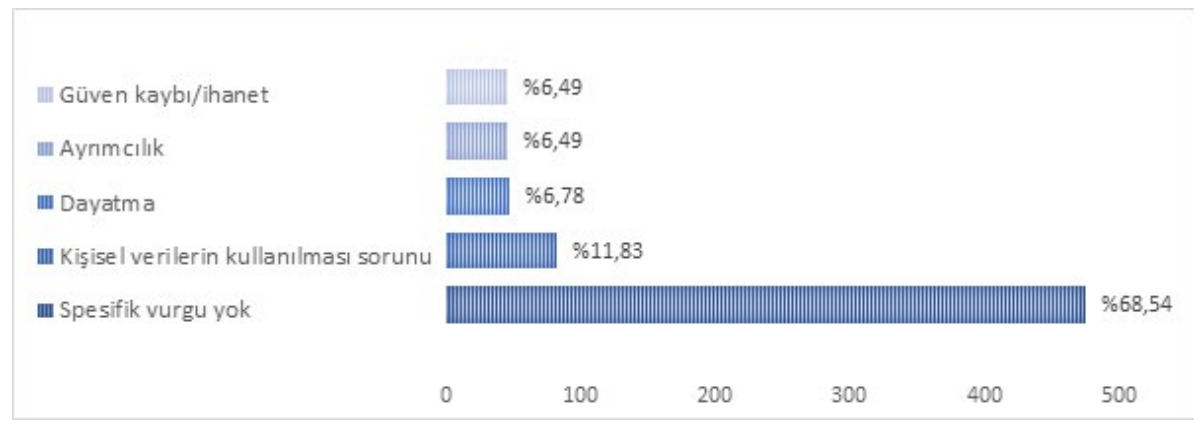

Çalışmada, tepkilerin ve tepki eleştirilerini içeren tweetlerin detaylı incelemesi de yapılarak tweetlerin taşıdıkları anlamlar ve mesajların odak noktaları açığa çıkarılmaya çalışılmıştır. Illk olarak tepki amacıyla atılan 693 tweetin $(\% 23,1)$ içerikleri incelenmiş ve tweetlerin \%68,54'ünün herhangi bir spesifik vurgusunun ( $n=475)$ olmadığı anlaşılmıştır. Tepkilerin sırasıyla, kişisel verilerin kullanılması sorununa ( $n=82, \% 11,83)$, dayatmaya $(n=47, \% 6,78)$ ve ayrımcılık $(n=45, \% 6,49)$ ile güven kaybı/ihanet $(n=45, \% 6,49)$ noktalarına odaklandıkları görülmüştür (Grafik 1).

Grafik 2. Tepkiyi Eleştiren Tweetlerin Alt Kategorilerinin Dağılımı

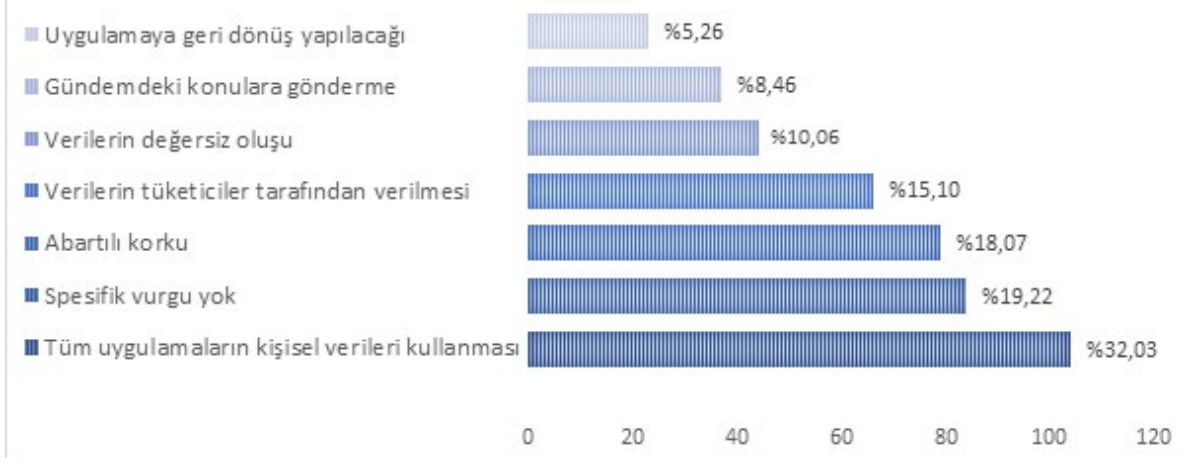

İkinci olarak, tepkilerin eleştirisini içeren 437 tweetin \%32,03'ünün, yalnızca WhatsApp'ın değil tüm uygulamaların kişisel verileri kullandığı gerçeğine ya da 
farklı bir değişle tüm uygulamaların benzer veya işbirliği içinde olduğu vurgusuna ( $n=104)$ işaret ettikleri, \%19,22'sinde ise spesifik bir vurgu ( $n=84)$ olmadığı anlaşılmıştır. Tweetlerde yer alan diğer eleştirilerin ise sırasıyla, abartılı korku ( $n=79$, $\% 18,07)$, verilerin tüketiciler tarafindan zaten çeşitli yollarla verilmesi ( $n=66$, $\% 15,10)$, verilerin değersiz olması ( $n=44, \% 10,06)$, gündemde daha önemli konular olması $(n=37, \% 8,46)$ ve uygulamaya geri dönüş yapılacağı $(n=23, \% 5,26)$ noktalarına odaklandıkları tespit edilmiştir (Grafik 2).

Tweetlerde WhatsApp uygulamasından farklı bir platformun isminin yer alıp almadığı da incelenmiştir. İnceleme esnasında hem metin içinde hem de hashtag kullanımı yoluyla farklı platformlara gönderme yapıldığı, bu platformların WhatsApp uygulamasına alternatif olarak sunuldukları ve özellikle tepkili olan kullanıcıların bu uygulamaları tercih edebileceklerine dikkat çekildiği görülmüştür. Incelenen 3.000 tweetin \%35,8'ini oluşturan 1.074 tweette en az bir alternatif mecra ismi bulunurken tweetlerin çoğunda ( $n=1.926, \% 64,2)$ herhangi bir alternatif mecra isminin yer almadığı tespit edilmiştir.

Twitter'da tweetlere, görseller ve yönlendirici linkler eklemek mümkündür ve fotoğraf veya video şeklinde olabilecek bu görseller ile linkler, mesajın taşıdığı anlamı pekiştirmek açısından işlevseldir. Çalışmada incelenen tweetlerde görsel veya link olup olmadığına ilişkin bir analiz gerçekleştirilmiş ve incelenen tweetlerin \%43,2'sinde ( $n=1.297$ ) görsellere veya yönlendirici linklere yer verildiği ancak $\% 56,8^{\prime}$ inde $(n=1.703)$ herhangi bir görsel ya da linkin bulunmadığı anlaşılmıştır.

Görsel veya link kullanılan 1.297 tweetin üst kategorilere göre çapraz dağılımlarına bakıldığında, en çok mizah unsuru $(n=569, \% 43,9)$ taşıyan tweetlerde, ikinci olarak ise haber/bilgi içeren ( $n=259, \% 20)$ tweetlerde görsel ve/veya link kullanıldığı anlaşılmıştır. Krize ilişkin tepki içeren tweetlerin ise yalnızca \%14,3'ünde ( $n=185)$ görsel veya linklere yer verildiği dikkat çekmiştir (Grafik 3).

Grafik 3. Görsel veya Link Kullanılan Tweetlerin Üst Kategorilere Göre Çapraz Dağılımları

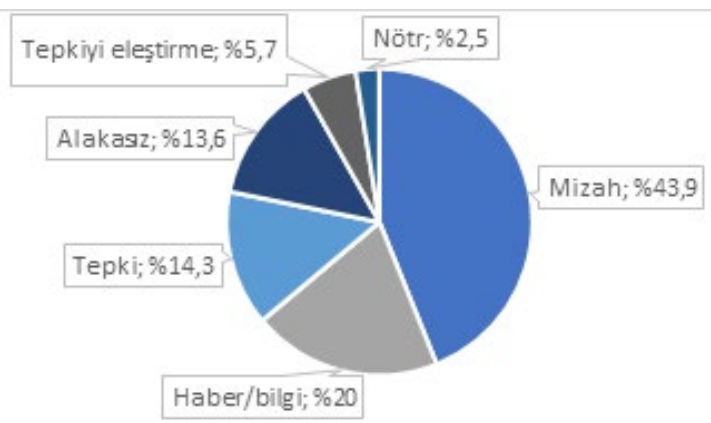


Çalışmanın amacı, \#WhatsAppSiliyoruz hashtagi ile atılan tweetleri incelemek olduğundan örneklemin tamamında bu etiketin olması aşikârdır. Öte yandan analiz esnasında bazı tweetlerde \#WhatsAppSilmiyoruz hashtaginin de kullanılması dikkat çekmiş olup bu doğrultuda da bir analiz gerçekleştirilmiştir. Buna göre analiz edilen tüm tweetlerin \%21,9'unda ( $n=656)$ her iki hashtagin bir arada kullanıldığı görülmüştür.

Her iki hashtagin bir arada kullanıldığı 656 tweetin üst kategorilere göre çapraz dağılımlarına bakıldığında ise ilk olarak mizah kategorisine ait tweetlerde ( $n=216$, $\% 32,9)$, ikinci olarak tepkiyi eleştiren tweetlerde ( $n=124, \% 18,9)$, üçüncü olarak ise haber/bilgi içeren tweetlerde ( $n=105, \% 16)$ bir arada kullanım olduğu tespit edilmiştir (Grafik 4).

Grafik 4. Her İki Hashtagin Bir Arada Kullanıldığı Tweetlerin Üst Kategorilere Göre Çapraz Dağılımları

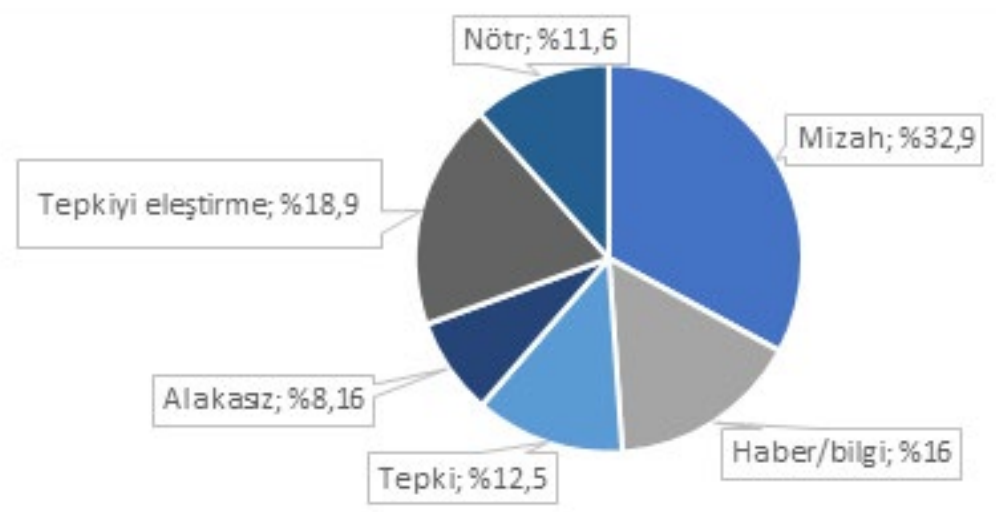

İçerik analizi doğrultusunda ortaya çıkan tüm bu bulguların yanı sıra tweetlerin kodlanması esnasında farklı unsurlar da dikkat çekmiştir. Bu bulgular araştırmacılar tarafindan ayrıca incelenmiştir. Bu bulgulardan ilki, kriz esnasında WhatsApp uygulamasının sözleşmeyi geri çekeceğine ilişkin bir haberin gündeme düşmesi sonucunda ortaya çıkmıştır. Teyit edilemeyen ve sonrasında "yanlış-yalan haber" olduğu ortaya çıkan bu bilginin, tweetlerin çoğunda yer aldığı, kullanıcıların bu bilgiye inanarak çeşitli yorumlarda bulundukları veya uygulamaya geri dönüş gerçekleştirdikleri görülmüştür. Az sayıda tweette haberin yanlış olduğuna ilişkin bilgilendirmeler yer alırken, yanlış bir haberin bu denli dolaşıma girmesi de bilgi kirliliği ve dezenformasyon tartışmaları bağlamında bir başka etik problemin göstergesi olarak değerlendirilmiştir. Buna göre incelenen tüm tweetlerin \%8,73'ünde yalan habere ilişkin pozitif ya da negatif açıdan bir bilginin yer aldığı görülmüştür. 
ilgi çekici bir diğer bulgu ise tweetlere de yansıyan "karmaşa veya kararsızlık" ile ilgilidir. Kriz karşısında tepki gösteren ancak hangi platformun daha güvenli olduğu konusunda kararsızlık yaşayan, bu kararsızlık sebebiyle de pek çok farklı uygulamayı indirmiş kullanıcılar olduğu tweetlerin incelemesi esnasında dikkat çekmiştir. Buna göre tweetlerin \%5,7'sinde konuyla ilgili karmaşaya ve yaşanan kararsızlığa gönderme olduğu tespit edilmiştir.

Bir başka bulgu ise tweetlerde, yerli bir uygulamaya duyulan intiyaca işaret edilmesidir. Buna göre tweetlerin \%2,3'ünde "yerli ve milli" bir uygulama yapılması gerektiği belirtilmiştir. Tüm bu bulguların yanı sıra incelenen tweetlerde oranları çok düşük olsa da başka unsurlara da dikkat çekildiği görülmüştür. Bunlar kısaca özetlendiğinde, kullanıcıların WhatsApp yerine tercih ettikleri yeni uygulamadan bekledikleri verimi alamadıkları, WhatsApp'a duydukları bağılığı zaman zaman dile getirdikleri, başta stickerlar (yapıştırma-çıkartma) olmak üzere WhatsApp uygulamasının sağladığı özelliklere özlem duydukları, krize yönelik tepkinin WhatsApp'ın kararı üzerine herhangi bir etkisi olmayacağı, WhatsApp'ı silenlerin aynı şirketin ürünleri olan Instagram, Facebook gibi uygulamaları kullanmaya devam ettikleri gibi konulara göndermeler yapıldığı görülmüştür.

\section{Tartışma ve Sonuç}

Kişisel verilerin korunması ile kullanımının düzenlenmesine ilişkin tartş̧malar, dijital uygulamalar söz konusu olduğunda dikkat çeken bir alan hâline gelmiştir. Pek çok farklı düzenleme ile sağlanmaya çalışılan veri güvenliği, dijital uygulamaların kullanııılarına sundukları sözleşmeler ve gizlilik politikaları ile koruma altına alınmaya çalışılmaktadır. Her ne kadar bu sözleşmelerin, taraflar arasında karşıııklı bilgi alışverişine ve rızaya dayandığı varsayılsa da hem kullanıııların konu hakkındaki bilgi ve farkındalık düzeyleri hem de uygulamaların sözleşme ilkelerinin kapsamı tartışmalı bir konudur. Araştırmalar, kullanıcıların çok az bir kısmının bu sözleşmeleri okuduklarını ve genellikle okumadan kabul edildiğini ortaya koymuştur (Custers vd., 2014; Steinfeld, 2016; Obar ve Oeldorf-Hirsch, 2020).

Literatürdeki bulgular, kullanııların kişisel verilerin güvenliğine ilişkin hassasiyetlerinin düşük olduğu varsayımını doğurmaktadır. Ancak popüler mesajlaşma programı WhatsApp'ın gizlilik politikasını değiştirerek verileri Facebook ile paylaşacağını duyurmasından sonra ortaya çıkan tepkiler, kullanıııların bu konudaki hassasiyetlerine dikkat çekmiştir. Çalışmada, tepkilerin dile getirildiği platformların başında gelen Twitter üzerinden bir analiz gerçekleştirilmiş ve tepkiler sonucu ortaya çıkan \#“\#WhatsAppSiliyoruz hashtagi ile atılan tweetler incelenmiştir. WhatsApp krizi karşısında kullanıı tepki ve yorumlarının incelenmesinin amaç- 
landığı çalışmanın bulguları ışığında şunları söylemek mümkündür. Kullanıcılar tarafindan atılan tweetlerde en çok mizah $(\% 32,9)$ unsurunun kullanıldığı görülmektedir. Buna göre kullanıcıların krizi mizahi bir dille ele aldıkları ve konuyla ilgili çeşitli meseleler hakkında esprili yorumlarda bulundukları anlaşılmıştır. Özellikle gündemde olan komik ve eğlenceli olayların, fotoğraf ve video olmak üzere görsellerin, karikatürlerin ve mizahi unsurların, WhatsApp krizine uyarlanarak kullanılması dikkat çekmiştir. Elde edilen bulgu mizahın, fikirlerin müzakeresinde önemli olduğu ve sosyal medyanın da güncel siyasi gelişmelerin değerlendirilmesinde önemli bir role sahip olduğu düşüncesinden hareketle Ayaşlıoğlu ve Aydın'ın (2021) yapmış oldukları çalışmanın sonuçlarıyla da örtüşmektedir. Yazarlar, kullanıcıların siyasi krizlere ve politik konulara ilişkin sosyal medya paylaşımlarının odak noktalarını incelemişler ve kullanıcıların görsel materyaller, kültürel referanslar ve popüler anlatılar üzerinden krizlere ilişkin bakış açılarını mizah yoluyla ifade etme yönünde güçlü bir motivasyona sahip olduklarını saptamışlardır. Mizahın bu kullanım biçimi, mizahın yalnızca bir eğlence ve güldürü unsuru olmaması ile de açıklanabilir. Buna göre mizahi unsurların tercih edilmesinin temel sebeplerinden biri Tamer'in (2011: 211) aktarımıyla, mizahın kaynağında eleştirinin olmasıdır. Peifer (2012: 266) ise mizahın, "başkalarına saldırmak, onları zayıflatmak ve insanlar, fikirler ve kurumlar hakkında yargı ve eleştiriler telaffuz etmek için bir silah" olarak kullanılabileceğini ifade etmektedir. Bu doğrultuda mizah kullanımına ilişkin bulgu bir bakış açısından, konuya ilişkin atfedilen önem derecesinin düşük olduğu yönünde değerlendirilebilirken bir başka bakış açısından ise mizahın eleştirel yönü bağlamında da bir iletişim ile ifade biçimi olarak değerlendirilebilir.

Öte yandan araştırma bulgularına göre mizahi unsurlardan sonra ikinci olarak tepki içeren tweetlerin $(\% 23,1)$, üçüncü olarak ise tepkileri eleştirenlerin tweetlerinin $(\% 14,6)$ olduğu saptanmıştır. Bu sonuç, kriz karşısında tepki gösterenler olduğu kadar gösterilen tepkileri garipseyenler, eleştirenler ya da gereksiz bulanlar olduğunu da göstermektedir. Tepki gösterenlerin tweetleri incelendiğinde, kullanıcıların genellikle kişisel verilerinin kullanılması yönünde $(\% 11,83)$ bir rahatsızlıkları olduğu sonucuna varılmıştır. Bu veri, kullanıcıların giderek daha fazla gizliliğe ve mahremiyete önem vermeye başladıklarının da bir göstergesi olarak değerlendirilebilir. Daha önce de belirtildiği gibi 2020 yılında yapılan bir araştırma, kullanıcıların veri paylaşımları konusunda daha bilinçli hâle geldiklerini ortaya koymuştur (Anant vd., 2020). Tepki paylaşımlarında yer alan dayatma $(\% 6,78)$, ayrımcılık $(\% 6,49)$ ve güven kaybı $(\% 6,49)$ gibi odak noktalarının ise birbirine yakın oranlarda olduğu görülmektedir. Buna göre tepkilerin önemli bir kısmı What- 
sApp’ın kararının tüm ülkeleri kapsamamasından ve kullanıcılara bir dayatma gibi sunulmasından kaynaklandığı anlaşılmaktadır. Uygulamanın değişiklikleri yalnızca belirli ülkelerle sınırlı tutması krizin boyutunu etkilerken kültürel ve siyasal tepkilerin ortaya çıkmasına da neden olmuştur.

Tepkileri eleştiren tweetler ise yine en çok kişisel verilerinin kullanılmasına $(\% 32,03)$ işaret ederken konu farklı bir perspektiften ele alınmakta ve yalnızca WhatsApp'ın değil WhatsApp'a alternatif olan tüm uygulamaların da kişisel verileri kullanması gerçeğine dikkat çekilmektedir. Bu bulgu, kişisel verilerin ticari kaygılar ile kullanılması gibi etik bir problemin ne kadar yaygın olduğu yönünde değerlendirilebilir ve pek çok kullanıcı tarafindan gizlilik sözleşmelerinin okunmadan onaylanması, kullanıcının neye izin verdiğini bilmemesi sonucunu doğurmaktadır. Okunmadan onaylanan sözleşmeler, kişisel verilerin ekonomik bir değer olarak kullanımını kolaylaştırmaktadır. Ek olarak eleştirilerin sırasıyla abartılı korku (\%18,07), kişisel verilerin kullanıcılar tarafindan zaten farklı yollarla paylaşılmış olması $(\% 15,10)$ ve verilerin değersiz oluşu $(\% 10,06)$ gibi noktalara da odaklandığı görülmüştür. Bu bulgu, gerçek kişilere ilişkin her türlü bilgi anlamına gelen kişisel verilerin, kullanıcılar nezdinde değersizleştirilmesi olarak değerlendirilebilir. Daha önce açıklandığı gibi kişisel veri bir yandan da özel hayatın gizliliği, mahremiyet, temel hak ve özgürlüklerin korunması ve etik değerler ile de ilgilidir ve bu bağlamda verinin değersizleştirilmesi başlı başına etik bir problemdir.

Çalışmada \%11,1 oranında da olsa \#WhatsAppSiliyoruz hashtagi ile atılmış konudan bağımsız ve alakasız tweetler olduğu bulgulanmıştır. Örneklemin tamamı düşünüldüğünde çok düşük sayılamayacak bu oran, gündemin popülaritesinin alternatif konulara aktarılmaya çalışılması olarak değerlendirilebilir. Buna göre gündeme olan ilgiden faydalanmak amacıyla, reklam, tanıtım, ilgi çekme, ilgi transferi gibi amaçlarla konuyla doğrudan bağlantısı olmayan çok sayıda tweette \#WhatsAppSiliyoruz hashtaginin kullanıldığı anlaşılmıştır.

Tweetlerde en çok mizahi unsurlara yer verildiği görülmüşken, fotoğraf ve video gibi görsel ya da link kullanımlarının da en çok mizahi $(\% 43,9)$ tweetlerde olduğu sonucuna varılmıştır. Buna göre görsellerin, mizahi anlatımı güçlendirdiği sonucuna varılabilmektedir. İkinci olarak görsel ve link paylaşımlarının haber içerikli tweetlerde (\%20) olduğu ve bunların habere yönlendirme amacıyla kullanıldığı sonucuna varılmıştır. Ancak analiz sırasında çok sayıda yanlış bilginin de dolaşıma girdiği dikkat çekmiştir. Başlı başına etik bir sorunsal olarak değerlendirilmesi gereken bilgi kirliliği ve yanlış/çarpıtılmış haberler, WhatsApp krizinde de net bir biçimde gözlemlenmiştir. Tepkiler sonrasında uygulamanın kararını geri çektiğine ilişkin bir haberin dolaşıma girerek çok sayıda tweette ve haber sitesinde yer al- 
dığı saptanmıştır. Herhangi bir resmî kaynağa dayanmayan ve teyit edilmemiş bir bilgi olarak kamuoyuna yansıyan bu haberin, kullanıcılarda kafa karışıklığı yaşanmasına yol açttğı, tepkilerin bu noktada değiştiği ve kullanıcıların bu habere inanarak uygulamaya geri dönmeye başladıkları görülmüştür. Habercilik açısından da etik bir problem olarak değerlendirilmesi gereken bu durum, özellikle krizler esnasında dezenformasyon sorununu bir kez daha tartışmaya açmıştır.

\section{Kaynakça}

Anant, V., Donchak, L., Kaplan, J., \& Soller, H. (2020). The consumer-data opportunity and the privacy imperative. McKinsey and Company. https://www.mckinsey. com/business-functions/risk/our-insights/the-consumer-data-opportunity-and-the-privacy-imperative Erişim tarihi: 01.03.2021

Ateşalp, S., \& Başlar, G. (2015). Katılımcı Kültür Tartş̧maları Ekseninde Sosyal Medyada Diziler: Kardeş Payı Örneği. E-journal of Intermedia, 2(1), 158-180.

Ayaşlıoğlu, E., \& Aydın, M. B. (2021). "Mocking Birds "Tweeting": The Use of Humor in Political Sharings and Posts on Social Media". Elif Esiyok (Ed.). Handbook of Research on New Media Applications in Public Relations and Advertising. 395-420. IGI Global.

Barbosa, S., \& Milan, S. (2019). Do not harm in private chat apps: Ethical issues for research on and with WhatsApp. Westminster Papers in Communication and Culture, 14(1), 49-65.

Benndorf, V., \& Normann, H. T. (2018). The willingness to sell personal data. The Scandinavian Journal of Economics, 120(4), 1260-1278.

Berg, B. L. \& Lune, H. (2019). Sosyal Bilimlerde Nitel Araştırma Yöntemleri. Konya: Eğitim.

Biber, A. B. (2021, 14 Ocak). WhatsApp'ın 'zorunlu' güncellemesi kullanıcıları nasıl etkileyecek?. TRT Haber. https://www.trthaber.com/haber/dunya/WhatsAppin-zorunlu-guncellemesi-kullanicilari-nasil-etkileyecek-545340.html Erişim tarihi: 02.03.2021

Bilir, F. (2021). Kişisel Verilerin Korunması Kişinin Kendisinin Korunmasıdır. TRT Akademi, 6(11), 172-181.

Burgess, J. \& Green, J. (2018). YouTube: Online video and participatory culture. Cambridge: Polity Press.

Castells, M. (2016). İletişim Gücü. İstanbul: İstanbul Bilgi Üniversitesi Yayınları.

Chau, C. (2010). YouTube as a participatory culture. New directions for youth development, 128, 65-74.

Ciszek, E. (2013). Advocacy and amplification: Nonprofit outreach and empowerment through participatory media. Public Relations Journal, 7(2), 187-213.

Custers, B., van der Hof, S., \& Schermer, B. (2014). Privacy expectations of social media users: The role of informed consent in privacy policies. Policy \& Internet, 6(3), 268-295. 
Dixit, P. (2021, 21 January). WhatsApp Fueled A Global Misinformation Crisis. Now, It's Stuck In One. BuzzFeed News. https://www.buzzfeednews.com/article/ pranavdixit/WhatsApp-misinfo-privacy-policy Erişim tarihi: 01.03.2021

Doğan, K., \& Arslantekin, S. (2016). Büyük veri: önemi, yapısı ve günümüzdeki durum. Ankara Üniversitesi Dil ve Tarih-Coğrafya Fakültesi Dergisi, 56(1), 15-36.

Ergen, Y. (2018). Büyük Veri, Sosyal Medya ve Etik: Facebook Örneğinde Bir Değerlendirme. Yeni Düşünceler, (10), 53-64.

Facebook (2021). Company Info. https://about.fb.com/company-info/ Erişim tarihi: 01.03.2021

Friedman, M. (1999). Consumer Boycotts: Effecting Change Through The Marketplace and The Media. Routledge.

Gartner (2021). Infonomics. https://www.gartner.com/en/information-technology/glossary/infonomics Erişim tarihi: 01.03.2021

Getdaytrends (2021). \#WhatsAppSiliyoruz Worldwide https://getdaytrends.com/trend/\%23WhatsAppSiliyoruz/\#otherLocations Erişim tarihi: 01.03.2021

Gökçe, O. (2019). Klasik ve Nitel İçerik Analizi. Ankara: Çizgi.

Hayes, A. F., \& Krippendorff, K. (2007). Answering the call for a standard reliability measure for coding data. Communication methods and measures, 1(1), 77-89.

IBM Corp. (2013). IBM SPSS Statistics for Windows, Version 22.0. Armonk, NY: IBM Corp. Jenkins, H. (2006). Convergence Culture: Where Old and New Media Collide. New York: New York University Press.

Jenkins, H. (2009). Confronting the challenges of participatory culture: Media education for the 21st century. Cambridge, Massachusetts: The MIT Press.

Jenkins, H., Shresthova, S., Gamber-Thompson, L., Kligler-Vilenchik, N., \& Zimmerman, A. M. (2016). By Any Media Necessary: The New Youth Activism. New York: New York University Press.

Kırık, A. M., \& Özcan, A. (2014). Bir Dijital Aktivizm Örneği: Akıllı Ağ Çeteleri (Smart Mobs). AJIT-e: Bilişim Teknolojileri Online Dergisi, 5(14), 61-78.

Kişisel Verileri Koruma Kurumu (2021, 12 Ocak). WhatsApp Uygulaması Hakkında Kamuoyu Duyurusu. https://www.kvkk.gov.tr/Icerik/6856/WhatsApp-UYGULAMASI-HAKKINDA-KAMUOYU-DUYURUSU Erişim tarihi: 02.03.2021

Kişisel Verilerin Korunması Kanunu (2021) https://www.mevzuat.gov.tr/MevzuatMetin/1.5.6698.pdf Erişim tarihi: 02.03.2021

Lomborg, S. (2012). Personal internet archives and ethics. Research Ethics, 9(1), 20-31.

Makarem, S. C., \& Jae, H. (2016). Consumer boycott behavior: An exploratory analysis of twitter feeds. Journal of consumer affairs, 50(1), 193-223.

Marr, B. (2020). Veri Stratejisi: Büyük Veri ve Nesnelerin İnterneti Nasıl Kar Getirir?. İstanbul: MediaCat.

Narin, B., Ayaz, B., Fırat, F., \& Fırat, D. (2017). Büyük Veri ve Gazetecilik Illişkisi Bağlamında Veri Gazeteciliği. AJIT-E, 8(30), 215-235.

Neuman, W. L. (2014). Social Research Methods: Qualitative and Quantitative Approaches. Essex, England: Pearson.

O'Connor, C., \& Joffe, H. (2020). Intercoder reliability in qualitative research: debates and practical guidelines. International Journal of Qualitative Methods, 19, 1-13. 
Obar, J. A., \& Oeldorf-Hirsch, A. (2020). The biggest lie on the internet: Ignoring the privacy policies and terms of service policies of social networking services. Information, Communication \& Society, 23(1), 128-147.

Öz, M., \& Kılıç, D. (2020). Kişisel Verilerin Çevrimiçi Mahremiyet Ile Iliş̧isinin İçerik Analizi Yöntemiyle İncelenmesi. Karamanoğlu Mehmetbey Üniversitesi Sosyal ve Ekonomik Araştırmalar Dergisi, 22(39), 206-224.

Özdemir Çakır, H. (2011). Tüketici Boykotlarının Kriz İletişimi Açısından Değerlendirilmesi. Çankırı Karatekin Üniversitesi Sosyal Bilimler Enstitüsü Dergisi, 1(2), 121-136.

Öztürk, Ş. (2015). Sosyal Medyada Etik Sorunlar. Selçuk Iletişim, 9(1), 287-311.

Park, C. S. (2013). Political carnivalism and an emerging public space: examination of a new participatory culture on Twitter. International Journal of Electronic Governance, 6(4), 302-318.

Peifer, J. T. (2012). Can We Be Funny? The Social Responsibility of Political Humor, Journal of Mass Media Ethics, 27(4), 263-276.

Quinn, K. \& Epstein, D. (2018). \#MyPrivacy: How Users Think About Social Media Privacy. In Proceedings of the International Conference on Social Media \& Society, Copenhagen, Denmark, 360-364.

Rekabet Kurulu (2021, 11 Ocak). Rekabet Kurulu Facebook ve WhatsApp hakkında resen soruşturma başlattı ve WhatsApp verilerinin paylaşılması zorunluluğunu durdurdu. https://www.rekabet.gov.tr/tr/Guncel/rekabet-kurulu-facebook-ve-WhatsApp-hakk-14728ae4f653eb11812700505694b4c6 Erişim tarihi: 02.03.2021

Rotman, D., Vieweg, S., Yardi, S., Chi, E., Preece, J., Shneiderman, B., Pirolli, P., \& Glaisyer, T. (2011). From Slacktivism to Activism: Participatory Culture in the Age of Social Media. Proceedings of the $\mathrm{CHI}$ '11 Extended Abstracts on Human Factors in Computing Systems. New York, NY: ACM, 819-822.

Smitko, K. (2012). Donor engagement through Twitter. Public Relations Review, 38(4), 633-635. Statista (2021, 9 February). Most popular global mobile messenger apps as of January 2021, based on number of monthly active users. https://www.statista. com/statistics/258749/most-popular-global-mobile-messenger-apps/ Erişim tarihi: 02.03.2021

Steinfeld, N. (2016). "I agree to the terms and conditions": (How) do users read privacy policies online? An eye-tracking experiment. Computers in Human Behavior, 55, 992-1000.

Tamer, A. (2011). “Kurtuluş Savaşı’ndan Tek Parti Dönemine İktidar ve Mizah Basını İlişkisi: Devlet Arşivimdeki İzler", Gülmenin Arkeolojisi ve Medyada Mizah Olgusu Bildiriler Kitabı, Önder Barlı ve Derya Tellan (Ed.), 211-223, Atatürk Üniversitesi Illetişim Fakültesi Ulusal İletişim Kongresi Erzurum.

Tombleson, B., \& Wolf, K. (2017). Rethinking the circuit of culture: How participatory culture has transformed cross-cultural communication. Public Relations Review, 43(1), 14-25.

Townsend, L., \& Wallace, C. (2016). Social media research: A guide to ethics. University of Aberdeen, 1, 16. https://www.gla.ac.uk/media/Media_487729_smxx.pdf Erişim tarihi: 01.03.2021

Trending Archive (2021). https://archive.twitter-trending.com/turkey/09-01-2021 Erişim tarihi: 01.03.2021 
Trending Topis.co (2021) \#WhatsAppSiliyoruz is trending topic on Twitter. http://trending-topics.co/search.php?u=\%23WhatsAppSiliyoruz Erişim tarihi: 01.03.2021

van Dijk, J. (2016). Ağ Toplumu. (Çev. Ö. Sakin), İstanbul: Kafka.

WhatsApp (2021a). WhatsApp Hakkında. https://www.WhatsApp.com/about/ Erişim tarihi: 01.03.2021

WhatsApp (2021b). Facebook Şirketleriyle nasıl çalışıyoruz. https://faq.WhatsApp.com/ general/security-and-privacy/how-we-work-with-the-facebook-companies?eea=1\&lang=tr Erişim tarihi: 01.03.2021

WhatsApp [@WhatsApp]. (2021c, January 12). We want to address some rumors and be $100 \%$ clear we continue to protect your private messages with end-to-end encryption. https://twitter.com/WhatsApp/status/1348839600333049857 Erişim tarihi: 01.03.2021

Zenna \& RepMan (2018). Sosyal Linçler, Marka Krizleri ve İtibar Araşttrma Sunumu. http://www.repman.com.tr/tr/wp-content/uploads/2018/06/Sosyal-Lin\%C3\%A7-ve-Marka-Krizleri-Ara\%C5\%9Ft\%C4\%B1rmas\%C4\%B1-RepStorm2018-V1.pdf Erişim tarihi: 01.03.2021 